\title{
Stereotype Threat ditinjau dari Self-Efficacy pada Resimen Mahasiswa (MENWA) Wanita di Universitas " $X$ "
}

\author{
Rahmah Saniatuzzulfa \\ Program Studi Psikologi Fakultas Kedokteran Universitas Sebelas Maret \\ rsaniatuzzulfa@gmail.com \\ Julia Nurfitri Ariaji \\ Program Studi Psikologi Fakultas Kedokteran Universitas Sebelas Maret \\ julianurf@gmail.com
}

\begin{abstract}
Abstrak
Resimen wanita merupakan kelompok minoritas dalam organisasi MENWA di Perguruan Tinggi karena kegiatan dalam MENWA tergolong lebih banyak melibatkan aktivitas fisik ini yang seringkali dianggap bahwa kegiatan ini lebih layak diperuntukkan untuk kaum laki-laki. Hal tersebut menyebabkan resimen wanita banyak merasakan adanya ancaman stereotip (stereotype threat) dari masayarakat ketika mengikuti kegiatan ini. Salah satu faktor yang berkaitan dengan stereotype threat adalah self-efficacy. Self-efficacy yang tinggi mampu membuat individu percaya akan kemampuan dirinya dan mampu menyesuaikan dirinya dengan ancaman yang mengintai dirinya. Penelitian ini bertujuan untuk mengetahui hubungan antara self-efficacy dengan stereotype threat pada resimen wanita. Metode penelitian menggunakan kuantitatif dengan teknik penggumpulan data menggunakan skala self-efficacy ( 28 aitem, $\alpha=0,846)$ dan skala stereotype threat (14 aitem, $\alpha=0,754)$. Penelitian dilakukan pada 40 orang resimen wanita yang dipilih dengan menggunakan total populasi yang ada. Hasil penelitian menunjukkan bahwa skala self-efficacy menentukan stereotype threat $(\mathrm{F}=46,022$, $\mathrm{p}<0,05)$. SE memberikan kontribusi sebesar $54,8 \%$ pada stereotype threat.
\end{abstract}

Kata Kunci: MENWA, resimen wanita, self-efficacy, stereotype threat

\section{Pendahuluan}

Tidak dapat dipungkiri, perbedaan karakteristik laki-laki dan perempuan masih sangat kental di mata masyarakat luas. Hal ini seringkali dikaitkan dengan stereotip gender yang menganggap pria cenderung berperilaku maskulin, dan wanita cenderung berperilaku feminim (Barron dan Byrne, 2003). Tidak berhenti sampai disini saja, stereotip gender yang ada pada laki-laki dan perempuan memengaruhi keterbatasan mereka dalam memilih pekerjaan (Sihite, 2007), 
misalnya, perawat lebih cocok untuk mereka yang memiliki gender feminim dan pemadam kebakaran untuk maskulin (Doering dan Thébaud, 2017).

Resimen mahasiswa (MENWA) merupakan Unit Kegiatan Mahasiswa di bawah Universitas yang berfungsi sebagai cadangan kekuatan negara dan oleh karenanya, organisasi ini mendapat pelatihan militer. Kegiatan MENWA yang berbasis pada aktivitas fisik ini dirasa lebih cocok untuk laki-laki yang memiliki karakter maskulin disebabkan fisik pria dinilai lebih kuat dibandingkan dengan wanita. Hal ini mengingat karakteristik dasar wanita yang cenderung lemah lembut, halus, dan penyabar sehingga seringkali wanita ditempatkan pada posisi pekerjaan yang sesuai dengan karakteristiknya tersebut (Uyun, 2002). Hal ini menjadi menarik ketika pada masa sekarang, banyak wanita yang mulai tertarik untuk ikut terlibat dalam kegiatan-kegiatan yang lebih banyak didominasi oleh laki-laki serta pekerjaan-pekerjaan yang membutuhkan kekuatan fisik, keberanian, bahkan sikap-sikap maskulin. Ketika mahasiswi ikut terlibat dalam kegiatan MENWA, masyarakat umum seringkali melihat mahasiswi tersebut memiliki kepribadian tomboi, sok pahlawan, dan sok pemberani. Meskipun wanita yang terlibat dalam bidang militer percaya dengan kemampuan mereka, memiliki fisik yang cocok, dan siap untuk menghadapi tantangan dalam dunia militer, mereka tetap paham bahwa lingkungan mereka akan memberikan tekanan pada peran gender mereka. Wanita ini dituntut untuk bekerja lebih keras dalam mengatasi tekanan tersebut dan menjadi memperhatikan setiap usaha yang dikerahkan karena khawatir akan menunjukkan performa yang buruk. Mentalitas inilah yang menyebabkan mereka lebih rawan terhadap stereotype threat (Maheshwari dan Kumar, 2016).

Ketika terdapat stereotip tertentu pada suatu kelompok, biasanya anggota dari kelompok tersebut menjadi merasa khawatir bahwa mereka dipandang sesuai dengan stereotip tersebut. Dalam konteks dunia militer, pria dilihat lebih kompeten dibandingkan dengan wanita (Archer, 2014). Penelitian yang dilakukan oleh Chemers (1997) telah menunjukkan bahwa stereotip wanita di bidang militer, secara signifikan memunculkan perasaan terancam di dalam diri, sehingga performa mereka pun menjadi lebih buruk. Boldry, Wood dan Kashy (2001) 
menjelaskan bahwa stereotip mengenai wanita di bidang militer antara lain seperti wanita memiliki karakter feminin yang mengganggu keefektifan performa mereka di bidang militer dan tidak cukup tangguh baik secara fisik maupun emosi. Sebagai hasilnya, ancaman stereotip ini menyebabkan mereka memandang karakteristik diri mereka sesuai dengan stereotip tersebut.

Berdasarkan hasil wawancara yang telah peneliti lakukan pada tiga resimen wanita menunjukkan bahwa stereotip gender pada masyarakat khususnya Jawa memang tidak sesuai dengan kegiatan yang digelutinya saat ini. Kegiatan yang ada di MENWA memang membutuhkan kemampuan fisik yang ekstra. Selain itu, beberapa pertanyaan dan komentar negatif seperti mengapa tertarik mengikuti kegiatan tersebut, kegiatan tersebut lebih cocok untuk kaum pria, dan kegiatan tersebut tidak sesuai dengan kodrat wanita karena kegiatan tersebut bersofat tomboi/maskulin.

Ancaman stereotip (stereotype threat) yang dirasakan oleh resimen wanita seperti pandangan negatif ketika mengikuti kegiatan yang banyak didominasi lakilaki dan komentar negatif ketika mengikuti kegiatan tersebut yang dirasa menyalahi kodrat wanita sebagai makhluk lemah lembut. Stereotype threat akan keaktifannya dalam kegiatan di bidang kemiliteran tersebut menimbulkan berbagai dampak negatif, antara lain seringkali memengaruhi performa mereka dalam bekerja, misalnya menjadi mudah cemas, merasa rendah diri, putus asa dan merasa kegiatan yang dipilihnya tersebut melanggar kodratnya sebagai wanita. Beberapa penelitian menunjukkan dampak dari ancaman stereotip yakni dapat membuat seseorang menyalahkan dirinya sendiri ketika menghadapi kegalalan, menurunnya kontrol diri, meningkatkan potensi depresi, menurunkan tingkat psychological well-being, memunculkan gangguan PTSD, kecemasan, dan perilaku memberontak (Inzlicht dan Kang, 2010; Koch, Muller, dan Sieverding, 2008; Tullett, Inzlicht, dan Kay, 2012).

Kecemasan akan ancaman stereotip berpotensi pada hal-hal negatif, misalnya menyebabkan resimen wanita memilih menghindar dari kelompoknya tersebut dan mengubah minatnya pada kegiatan-kegiatan yang tidak sesuai dengan gendernya tersebut. Individu memilih mengambil jarak dan melepaskan diri dari 
kelompoknya ketika ia merasakan adanya ancaman dari lingkungan sekitarnya (Von Hippel, W., Von Hippel, C., Conway, Preacher, Schooler, dan Radvansky, 2005). Gambaran tentang dampak negatif dari kecemasan akan steoretip ini dapat pula dilihat pada Steele, James, dan Barnett (2002) dalam studinya tentang dominasi laki-laki di bidang-bidang Pendidikan tertentu, wanita cenderung memilih untuk berpikir ulang tentang pilihannya tersebut.

Ancaman (threat) yang dirasakan individu dipengaruhi oleh beberapa faktor, antara lain lain sifat kepribadian dan karakteristik personal (personality traits and related personal characteristics), perilaku dan proses kognitif (attitudes and related cognitions), kontak antar kelompok (intergroup contact), dinamika/hubungan antar kelompok (intergroup relations), dan faktor situasional (situational factors) (Stephan, Ybarra, dan Morrison, 2009).

Salah satu faktor yang akan ditinjau lebih lanjut yaitu terkait dengan sifat kepribadian dan karakteristik personal (personality traits and related personal characteristics), yaitu self-efficacy. Dikatakan oleh Bandura (2003), efikasi berarti keyakinan individu pada kemampuannya mengatur dan melakukan kegiatan untuk mencapai suatu prestasi. Keyakinan diri akan kemampuannya tersebut dapat membantu memotivasi individu dalam mencapai cita-cita dan tujuannya meskipun banyak halangan dari lingkungan sekitar.

Beberapa penelitian menunjukkan bahwa self-efficacy ini memiliki dampak yang signifikan terhadap performa dan motivasi seseorang. Penelitian Chung, Erhart, Holcombe-Ehrhart, Hattrup, dan Solamon (2010) menyatakan bahwa self-efficacy berperan penting dalam menurunnya performa orang dengan latar belakang ras Afrika-Amerika ketika menghadapi ancaman stereotipnya. Selain itu, Steele dan Aronson (1995) juga menjelaskan bahwa performa buruk, seperti efikasi diri dan evaluasi diri negatif muncul ketika menghadapi ancaman stereotip ini. Keller (2002) juga menjelaskan bahwa implementasi dari efikasi diri yang rendah, yaitu self-handicapping berkaitan erat dengan kemunculan ancaman berupa stereotip yang negatif.

Schunk dan Meece (2005) menjelaskan bahwa apabila individu memiliki self-efficacy yang tinggi maka ia mampu menganalisa situasi serta permasalahan 
yang sedang dihadapi sehingga dapat menemukan penyelesaian yang tepat. Sebaliknya, apabila seseorang memiliki self-efficacy yang rendah, maka mereka mudah putus asa dan mudah merasa tertekan ketika memiliki permasalahan sehingga sulit bagi mereka untuk dapat menyelesaikan permasalahan.

Ketika individu memiliki self-efficacy yang tinggi, maka ia tidak akan mudah terdistraksi oleh cemoohan lingkungan akan aktivitas yang dilakukannya. Ia cukup percaya diri dengan kemampuan yang dimilikinya meskipun dinilai negatif oleh lingkungannya. Hal ini didukung oleh penelitian yang dilakukan Wang, Zhou, Tan, Zhang (2017) pada 46 atlet menunjukkan bahwa self-efficacy dapat memediasi dampak pada aktivititas stereotype dalam mengerjakan tugas.

Penelitian ini bertujuan untuk mengetahui hubungan antara self-efficacy dengan stereotype threat pada resimen mahasiswa (MENWA) wanita. Apabila skor self-efficacy tinggi, maka stereotype threat rendah. Sehingga diharapkan resimen mahasiswa, khususnya wanita memiliki self-efficacy yang tinggi agar tidak terkena stereotype threat.

\section{Metode Penelitian}

Responden dalam penelitian ini adalah resimen mahasiswa wanita Universitas " $\mathrm{X}$ " yang berjumlah 40 orang. Pengambilan sampel menggunakan teknik studi populasi, yakni dengan menggunakan seluruh populasi yang ada disebabkan karena jumlah responden yang terbatas.

Penelitian ini menggunakan dua macam skala, yaitu:

1. Skala self-efficacy

Menggunakan modifikasi General Self-Efficacy Scale (Schwarzer dan Jerusalem, 1995) berdasarkan dimensi yang dicetuskan Bandura (2009), yaitu magnitude (tingkat), generality (keadaan umum), dan strength (kekuatan). Berjumlah 28 aitem dengan nilai reliabilitas 0,846.

2. Skala stereotype threat

Menggunakan modifikasi skala SIAS (Social Identities and Attitudes Scale) yang disusun oleh Picho dan Brown (2011). Aspek stereotype threat yang digunakan adalah domain identification, group 
identification, stigma consciousness, dan negative affect. Berjumlah 14 aitem dengan nilai reliabilitas 0,754 .

Penelitian ini menggunakan analisis regresi linier sederhana yang sebelumnya dilakukan uji asumsi dasar dan uji asumsi klasik. Perhitungan analisis data menggunakan program Statistical Product and Service Solution (SPSS) versi 20.0 .

\section{Hasil dan Pembahasan}

Uji Asumsi Dasar dan Klasik

Uji asumsi dasar meliputi uji normalitas dan uji liniearitas. Berdasarkan hasil uji normalitas menggunakan One-Sample Kolmogrov-Smirnov Test, didapatkan hasil bahwa skala self-efficacy memiliki nilai $\mathrm{p}>0,05(0,452>0,05)$ dan skala stereotype threat memiliki nilai $\mathrm{p}$ nilai $\mathrm{p}>0,05(0,971>0,05)$. Dari data tersebut, dapat disimpulkan bahwa persebaran data bersifat normal. Kemudian hasil uji linieritas menunjukkan nilai $\mathrm{p}<0,05$. Dari data tersebut, dapat disimpulkan bahwa terdapat hubungan linier antara self-efficacy dengan stereotype threat.

Uji asumsi klasik meliputi uji heteroskedastisitas dan uji autokorelasi. Hasil uji heteroskedastisitas menunjukkan bahwa titik-titik data menyebar secara tidak beraturan dan tidak berpola. Hal ini menunjukkan model regresi bebas dari asumsi heteroskedatisitas. Hasil uji autokorelasi menggunakan run-test menunjukkan bahwa Nilai Asymp. Sig. (2-tailed) sebesar 0, 873, dimana lebih besar dari 0,05 sehingga tidak terdapat gejala autokorelasi.

Uji Hipotesis

Tabel 1. Uji Simulan (F)

ANOVA $^{\text {a }}$

\begin{tabular}{llrrrrr}
\hline Model & & Sum of Squares & df & Mean Square & F & Sig. \\
\hline \multirow{2}{*}{1} & Regression & 354,373 & 1 & 354,373 & 46,022 &, $000^{\mathrm{b}}$ \\
\cline { 2 - 8 } & Residual & 292,602 & 38 & 7,700 & & \\
\cline { 2 - 8 } & Total & 646,975 & 39 & & & \\
\hline
\end{tabular}

a. Dependent Variable: Stereotype Threat

b. Predictors: (Constant), Self Efficacy 
Berdasarkan perhitungan, $\mathrm{F}_{\text {hitung }}$ yang diperoleh sebesar 46,022 dengan $F_{\text {tabel }}$ sebesar 4,12, maka dapat disimpulkan $F_{\text {hitung }}>F_{\text {tabel }}$, dengan nilai signifikasi $\mathrm{p}<0,05$. Berdasarkan hasil tersebut dapat disimpulkan bahwa hipotesis diterima yaitu terdapat hubungan antara self-efficacy dengan stereotype threat resimen mahasiswa (MENWA) wanita di Universitas "X".

1. Analisis Deskriptif

Berikut ini merupakan hasil kategorisasi setiap variabel.

Tabel 2. Kriteria dan Kategori Responden Penelitian

\begin{tabular}{|c|c|c|c|c|}
\hline \multirow[t]{2}{*}{ Variabel } & \multicolumn{2}{|c|}{ Kategorisasi } & \multicolumn{2}{|c|}{ Komposisi } \\
\hline & Kategorisasi & Skor & Jumlah & Persentase \\
\hline \multirow[t]{5}{*}{ Stereotype Threat } & Sangat rendah & $12 \leq X<19,2$ & 0 & $0 \%$ \\
\hline & Rendah & $19,2 \leq X<26,4$ & 9 & $22,5 \%$ \\
\hline & Sedang & $26,4 \leq X<33,6$ & 26 & $65 \%$ \\
\hline & Tinggi & $33,6 \leq X<40,8$ & 5 & $12,5 \%$ \\
\hline & Sangat tinggi & $40,8 \leq X<48$ & 0 & $0 \%$ \\
\hline \multirow[t]{5}{*}{ Self-efficacy } & Sangat rendah & $28 \leq X<44,8$ & 0 & $0 \%$ \\
\hline & Rendah & $44,8 \leq X<61,6$ & 0 & $0 \%$ \\
\hline & Sedang & $61,6 \leq X<78,4$ & 1 & $2,5 \%$ \\
\hline & Tinggi & $78,4 \leq X<95,2$ & 35 & $87,5 \%$ \\
\hline & Sangat tinggi & $95,2 \leq X<112$ & 4 & $10 \%$ \\
\hline
\end{tabular}

2. Persamaan Regresi

Tabel 3 Persamaan Regresi

\begin{tabular}{|c|c|c|c|c|c|c|}
\hline \multirow{2}{*}{\multicolumn{2}{|c|}{ Model }} & \multicolumn{2}{|c|}{ Unstandardized Coefficients } & \multirow{2}{*}{$\begin{array}{c}\begin{array}{c}\text { Standardized } \\
\text { Coefficients }\end{array} \\
\text { Beta }\end{array}$} & \multirow[t]{2}{*}{$\mathrm{t}$} & \multirow[t]{2}{*}{ Sig. } \\
\hline & & $\mathrm{B}$ & Std. Error & & & \\
\hline \multirow{2}{*}{1} & (Constant) & 78,529 & 7,281 & & 10,786 & 000 \\
\hline & SE &,- 559 &, 082 &,- 740 & $-6,784$ & 000 \\
\hline
\end{tabular}

Berdasarkan persamaan regresi $\mathrm{y}=$ constant $+\mathrm{bx}_{1}$, maka $\mathrm{y}=78,529-0,559 \mathrm{x}_{1}$. Artinya, apabila self-efficacy ditingkatkan sampai nilai 10, maka stereotype threat akan menjadi 72,939. Semakin tinggi self-efficacy, maka semakin rendah stereotype threat.

Berdasarkan hasil uji hipotesis hubungan antara self-efficacy dengan stereotype threat resimen mahasiswa (MENWA) wanita di Universitas

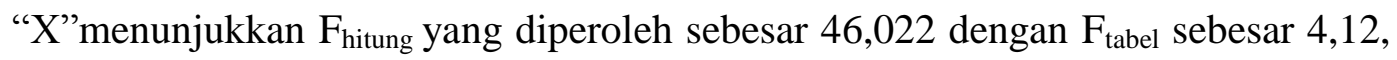
maka dapat disimpulkan $F_{\text {hitung }}>F_{\text {tabel }}$, dengan nilai signifikasi $\mathrm{p}<0,05$. Stereotype threat dipengaruhi oleh beberapa faktor, faktor eksternal dalam hal ini berkaitan 
dengan kelompok, organisasi, faktor situasional dan faktor internal, termasuk didalamnya kepribadian. Individu yang memiliki kepribadian mudah putus asa, mudah cemas seringkali membuat individu merasa tidak nyaman jika mendapat kritik sehingga mereka mudah mengalami tekanan stereotype threat (Stephan, Ybarra, dan Morrison, 2009). Oleh karena itu, individu yang memiliki kepercayaan diri (self-efficacy) yang tinggi, ia akan menganggap kritik sebagai pembangun atau masukan bagi kebaikan kehidupannya kedepan. Mereka tidak akan mudah merasakan adanya stereotype threat yang dapat menghalanginya mencapai cita-citanya.

Hasil penelitian ini mendukung penelitian terdahulu yang dilakukan Schweinle dan Mims (2009), self-efficacy menjadi prediktor yang kuat dalam prestasi akademis anak-anak. Ketika seseorang memiliki self-efficacy yang tinggi mereka akan mematahkan ekspektasi yang buruk mengenai kemampuan mereka. Sehingga mereka akan lebih baik dalam menangani efek buruk yang disebabkan stereotype threat pada performa mereka. Self-efficacy dan rasa percaya bahwa seseorang dapat menghadapi tekanan yang bersifat merugikan, memberikan kontribusi yang besar pada pencapaian yang akan diraih individu tersebut (Bandura, Barbaranelli, Caprara, dan Pestorelli, 1996).

Dalam proses efikasi diri ini, ketika seseorang menilai dirinya secara negatif akan menimbulkan proses kognitif yang bersifat negatif pula sehingga mempengaruhi performanya secara efektif (Steele dan Aroson, 1995). Selfhandicapping merupakan salah satu implementasi dari efikasi diri yang negatif. Tindakan ini mereka lakukan sebagai atribusi dari performa mereka yang mampu mereka kerahkan secara maksimal dan pembatas bagi mereka untuk meraih kesuksesan. Keller (2002) menjelaskan bahwa kecenderungan untuk menunjukkan self-handicapping ini berkaitan erat dengan kemunculan ancaman berupa stereotype yang negatif. Individu ini memiliki kecenderungan yang kuat untuk mencari atribusi terhadap menurunnya performa mereka.

Myers (2012) mengatakan bahwa self-efficacy merupakan keyakinan diri akan kompetensi yang dimilikinya. Hal ini berkaitan dengan salah satu dimensi efikasi diri dari Bandura (2009) yaitu strength. Strength merupakan kekuatan 
keyakinan individu dalam menyelesaikan tugas. Keyakinan dapat muncul ketika individu tersebut memiliki efikasi diri yang tinggi (Setiawan, Hardjajani, Hardjono, 2014). Keyakinan akan kemampuan ini penting untuk dimiliki agar dapat mengatasi permasalahan yang dihadapinya sehingga ia tidak mudah putus asa dalam mencapai cita-citanya. Keyakinan dan keinginan yang kuat pada individu dapat membuat individu mampu bertahan terhadap segala ancaman. Sehingga dapat disimpulkan bahwa apabila self-efficacy tinggi, maka stereotype threat rendah. Begitu juga sebaliknya.

Berdasarkan kategorisasi pada penelitian ini, stereotype threat resimen wanita MENWA menunjukkan sangat rendah sebesar 0\%; rendah sebesar 22,5\%; sedang sebesar 65\%, tinggi sebesar 12,5\%; dan sangat tinggi sebesar 0\%. Oleh karena itu, sebagian besar resimen wanita MENWA menunjukkan stereotype threat dalam tingkat sedang, artinya ancaman stereotip yang dirasakan resimen wanita dalam batas wajar. Sedangkan pada variabel self-efficacy menunjukkan berada pada kategori sangat rendah sebesar 0\%; rendah sebesar 0\%; sedang sebesar 2,5\%, tinggi sebesar 87,5\%; dan sangat tinggi sebesar 10\%. Oleh karena itu, sebagian besar resimen wanita MENWA menunjukkan tingkat self-efficacy yang tinggi, artinya ia memiliki kepercayaan diri yang baik. Tingginya selfefficacy seseorang dapat meningkatkan harga diri, kepercayaan diri, dan sikap optimis sehingga dapat meminimalisir terjadinya perasaan terancam akibat adanya stereotype dari lingkungan sekitar karena seseorang dapat mengelola pikiran, perilaku, dan perasaannya (Ackerman, 2018).

Persentase sumbangan pengaruh yang diberikan self-efficacy dengan stereotype threat sebesar 54,8\%, sementara sisanya sebesar 45,2 \% merupakan sumbangan dari pengaruh factor-faktor lain di luar variabel penelitian yang tidak diteliti oleh peneliti, misalnya tipe-tipe kepribadian, budaya organisasi, dinamika kelompok, dan interaksi dengan anggota kelompok. Self-efficacy yang tinggi pada individu dapat mengarahkan individu untuk bekerja lebih terarah sesuai dengan tujuan utamanya, sehingga individu tersebut akan lebih mudah mengatasi rintangan yang menghalanginya, terhindari dari depresi, dan dapat mencapai kebahagiaan hidup (Schunk dan Meece, 2005) 


\section{Kesimpulan dan Saran}

Berdasarkan hasil penelitian, maka dapat ditarik kesimpulan terdapat hubungan yang signifikan antara self-efficacy dengan stereotype threat resimen mahasiswa (MENWA) wanita di Universitas " $\mathrm{X}$ ". Terdapat beberapa saran yang dapat diberikan, antara lain untuk peneliti selanjutnya yang tertarik untuk meneliti dengan variabel yang sama dengan penelitian ini diharapkan dapat meneliti di lokasi yang berbeda, dengan jumlah sampel penelitian yang lebih banyak, dan memperluas kriteria subjek penelitian agar lebih beragam. Selain itu, peneliti selanjutnya yang dapat pula menguji variabel lain yang belum disertakan dalam penelitian ini, seperti: budaya organisasi, dinamika kelompok. Selain itu, dengan terbuktinya hipotesis ini, maka peneliti menyarankan untuk anggota resimen mahasiswa khususnya wanita dapat meningkatkan self-efficacy dengan cara lebih mengasah soft-skill dalam bidang kemiliteran dan mengikuti pelatihan pengembangan diri agar tehindar dari stereotype threat.

\section{DAFTAR PUSTAKA}

Ackerman, C. (2018). What is Self-Efficacy Theory in Psychology? Definition \& Examples. https://positivepsychologyprogram.com/self-efficacy

Archer, E. M. (2014). The power of gendered stereotypes in the US marine corps. Armed Forces \& Society, 39, (359-391).

Bandura, A., Barbaranelli,C., Caprara, G. V., \& Pastorelli, C. (1996). Multifaceted impact of self-efficacy beliefs on academic functioning. Child Development, 67(3), 1206-1222. doi:10.2307/1131888.

Bandura, A. (2009). Self-Efficacy in Changing Societies. Cambridge: Cambridge University Press.

Barron, A. R. \& Byrne, D. (2003). Psikologi Sosial (edisi kesepuluh). Jakarta: Erlangga.

Boldry, J., Wood, W., \& Kashy, D. A. (2001). Gender stereotypes and the evaluations of men and women in military training. Journal of Social Issues, 57, 689-705, 
Chemers, M. M. (1997), An integrative theory of leadership. New York, NY: Psychology Press.

Chung, B. G., Ehrhart, M. G., Holcombe-Ehrhart, K., Hattrup, K., Solamon, J. (2010). Stereotype threat, state anxiety and specific self-efficacy as predictors of promotion exam performance. Group Organ Manage, 35, 77-107. doi: 10.1177/1059601109354839

Doering, L. \& Thébaud, S. (2017). The Effects of Gendered Occupational Roles on Men's and Women's Workplace Authority: Evidence from Microfinance. American Sociological Review, 82 (3), 542-567.

Inzlicht, M., \& Kang, S. K. (2010). Stereotype threat spillover: How coping with threats to social identity affects aggression, eating, decision making, and attention. Journal of Personality and Social Psychology, 99(3), 467-481. http://dx.doi.org/10.1037/a0018951

Keller, J. B. (2002). Stereotype threat and women's math performance: Selfhandicapping as a strategic means to cope with obstrusive negative performance expectations. Sex Roles, 47, 193-198. Doi: 10.1023/A: 1021003307511

Koch, S., Müller, S. M., \& Sieverding, M. (2008). Women and computers: Effects of stereotype threat on attribution of failure. Computers \& Education archive Journal, 51(4), 1795-1803.

Kray, L. J., Galinsky, A., \& Thompson, L. (2002). Reversing the gender gap in negotiations: An exploration of stereotype regeneration. Organizational Behavior and Human Decision Processes, 87, 386410. Google Scholar, Crossref.

Maheshwari, N., \& Kumar, V. V. (2016). Military Psychology: Concepts, Trends and Interventions. India: SAGE Publications.

Myers, D. G. (2012). Psikologi Sosial (Social Psychology). Jakarta: Salemba Humanika.

Picho, K. dan Brown, S. W. (2011). Can Stereotype Threat Be Measured? A Validation of the Social Identities and Attitude Scale (SIAS). Journal of Advanced Academics, 22(3), pp. 374-411.

Schunk, D. H., \& Meece, J L. (2005). Self-Efficacy Development in Adolescences. United State of America: University of Kentucky.

Schwarzer, R., \& Jerusalem, M. (1995). Geberalized Self-Efficacy Scale. In J. Weinman, S. Wright, \& M. Johnson, Measure in Health Psychology: 
A user's portofolio. Causal and Control Beliefs (pp. 35-37), Windsor, UK: NFER-NELSON.

Schweinle, A., dan Mims, G. (2009). Mathematics Self-Efficacy: Stereotype Threat Versus Resilience. Springer Link Social Psychology of Education 12:501.

Setiawan, A., Hardjajani, T., Hardjono. (2014). Hubungan antara Kecerdasan Adversitas dan Efikasi Diri dengan Keaktifan dalam Organisasi Kemahasiswaan di Program Studi Psikologi Fakultas Kedokteran Universitas Sebelas Maret. Jurnal Candrajiwa, Universitas Sebelas Maret, 2, 5.

Sihite, R. (2007). Suatu Tinjauan Berwawasan Gender. Jakarta: Raja Grafindo Persada.

Steele, C. M. \& Aronson, J. (1995). Stereotype threat and the intellectual test performance of African Americans. J Pers Social Psychology, 69(5), 797-811. Retrieved from: https://www.ncbi.nlm.nih.gov/pubmed/7473032

Steele, J., James, J. B., \& Barnett, R. (2002). Learning in a Man's world: Examining the Perceptions of Undergraduate Women in MaleDominated Academic Areas. Psychology of Women Quarterly, 26, 4650 .

Stephan, W. G., Ybarra, O., \& Morrison, K. R. (2009). Intergroup Threat Theory . In T. D. Nelson (Ed.). Handbook of prejudice, stereotyping, and discrimination (pp. 43-59). New York: Psychology Press.

Tullett, A. M., Inzlicht, M., \& Kay, A. (2012). The Anxiety-Reducing power of belief: Contemplating belief systems is associated with lower ERN amplitude. New York: 5th Annual Meeting of the Social \& Affective Neuroscience Society.

Uyun, Q. (2002). Peran Gender dalam Budaya Jawa. Jurnal Psikologika, 13(VII).

Von Hippel, W., Von Hippel, C., Conway, L., Preacher, K. J., Schooler, J. W., \& Radvansky, G. A. (2005). Coping with Stereotype Threat: Denial as an Impression Management Strategy. Journal of Personality and Social Psychology, 89, 22-35

Wang, P., Zhou, P., Tan, C., Zhang, P. (2017). Effect of Self-Efficacy in Stereotype Activation. Social Behavior and Personality an International Journal Vol.45 No. 3. New Zealand. 